\title{
Genetic polymorphisms of STAT3 correlated with prognosis in diffuse large B-cell lymphoma patients treated with rituximab
}

\author{
Yunfei $\mathrm{Hu}^{1,2 \dagger}$, Ning Ding ${ }^{1 \dagger}$, Xuan $\mathrm{Jin}^{3}$, Lixia Feng ${ }^{1}$, Lingyan Ping ${ }^{1}$, Yuqin Song ${ }^{1 *}$ and Jun Zhu ${ }^{1 *}$
}

\begin{abstract}
Background: Rituximab in the combination of CHOP chemotherapy has been widely used as the standard treatment for several kinds of B-cell non-Hodgkin lymphoma (B-NHL). Inactivation of phosphorylation of STAT3 plays an essential role in rituximab-induced anti-proliferative activity in B-cell lymphoma. However, the relationship between STAT3 genetic polymorphisms and clinical response to standard frontline treatment with rituximab has not been well illustrated yet.
\end{abstract}

Methods: In this study we analyzed the STAT3 polymorphisms and prognosis of 166 diffuse large B-cell lymphoma (DLBCL) patients who were treated with rituximab from 2007 to 2010. Determination of the STAT3 polymorphisms of rs2293152 from genomic DNA was achieved by Sanger chain termination sequencing.

Results: We did not observe obvious correlation between patients' disease features and STAT3 polymorphisms, but patients with homozygous genotypes at rs2293162 showed a trend of higher CR rate than those with the heterozygous genotype, especially in non-GCB subgroup $(p=0.011)$. Furthermore, homozygous genotypes $\mathrm{GG}$ and CC also showed advantages of long-term survival compared with heterozygous genotype patients $(p=0.022)$.

Conclusions: These results suggest that STAT3 polymorphisms could be a suitable biomarker related to clinical outcome of DLBCL patients treated with rituximab.

Keywords: Diffuse large B-cell lymphoma, STAT3, Single nucleotide polymorphism, Rituximab

\section{Background}

Diffuse large B-cell lymphoma (DLBCL) is the most common B-cell non-Hodgkin lymphoma (B-NHL) subtype [1]. The introduction of rituximab plus cyclophosphamide/ doxorubicin/vincristine/prednisone (R-CHOP) chemotherapy is considered as the standard treatment for DLBCL patients, which dramatically improves the treatment outcome and prognosis [2]. However, a great number of B-NHL patients treated with this immunotherapy still develop primary and secondary resistance to rituximab [3]. Thus, novel prognostic factors are being explored to predict treatment outcome.

\footnotetext{
*Correspondence: songyuqin622@sina.com; zhu-jun@bjcancer.org ${ }^{\dagger}$ Equal contributors

'Key laboratory of Carcinogenesis and Translational Research (Ministry of Education), Department of Lymphoma, Peking University Cancer Hospital \& Institute, No.52 Fucheng Road, Haidian District, Beijing 100142, China Full list of author information is available at the end of the article
}

STAT3 is a member of the signal transducer and activator of transcription (STAT) family, which regulates many cellular and biological processes such as cell proliferation, division, and apoptosis via mediation of related genes expression $[4,5]$. Constitutively activated STAT3 has been demonstrated to be essential for the proliferation and survival of DLBCL cells, which provides a prognostic indicator and ideal target for DLBCL treatment [6,7]. Despite the activation of antibody-dependent cellular cytotoxicity (ADCC) and complement-dependent cytotoxicity (CDC), many studies have demonstrated that rituximab could also induce apoptosis by inhibiting phosphorylation of STAT3 in DLBCL cells $[8,9]$. We hypothesized that polymorphic differences in STAT3 may account for distinct clinical efficacy of rituximab in DLBCL patients.

In our study, initially several important single nucleotide polymorphisms (SNPs) in STAT3 (including rs2293152, rs6503695, and rs12949918), which have been associated 
with gene expression and lymphoma risk [10,11], were analyzed in 166 peripheral blood specimens from DLBCL patients treated with rituximab. During the following investigation of relationships between the polymorphisms and clinical outcome, we eventually identified the prognostic significance of STAT3 polymorphisms in rs2293152, which could be a suitable predictor related to rituximab efficacy.

\section{Results}

\section{Patients' characteristics}

The general characteristics of the patients (82 male and 84 female patients) in this study are summarized in Table 1. Sixty-three patients (38.0\%) exhibited B symptoms. Eighty-eight patients (53.0\%) were in stages 3 or 4, and 50 patients (30.1\%) had intermediate-to-high or high international prognostic index (IPI) scores. Bone marrow was involved by lymphoma in 5 patients (3.0\%) at diagnosis. R-CHOP or R-CHOP like treatment as a frontline regimen was administrated to 166 patients whose clinical efficacy was evaluable for this study.

\section{STAT3 polymorphisms}

STAT3 polymorphisms at rs2293152 in 166 patients were identified (Table 2). Thirty-one patients (18.7\%) had homozygous CC genotype; 57 patients (34.3\%), GG; and 78 patients (47.0\%), heterozygous CG. The frequency of the $C$ allele in DLBCL patients was $44.7 \%$, and that of the $\mathrm{G}$ allele was $55.3 \%$. The genotype distribution of the DLBCL population enrolled in our study was in HardyWeinberg equilibrium with regard to the STAT3 polymorphisms examined.

\section{Correlation analysis between STAT3 polymorphisms and clinical features of DLBCL patients}

Analysis of STAT3 polymorphisms of rs2293152 suggested that patients with homozygous CC and GG genotypes had a higher tendency to be male than those with the heterozygous genotype $(p=0.042)$. Furthermore, our data showed that an elevated $\beta 2-\mathrm{MG}$ level might be less frequent in patients with homozygous genotypes than in those with the heterozygous CG genotype $(p=0.091)$. The distribution of this STAT3 polymorphisms did not correlate with the germinal center B cell-like (GCB) and non-GCB subtypes ( $p=0.229$; Table 1$)$.

\section{Impact of the STAT3 polymorphisms on the curative} effect of rituximab

Of the 166 patients evaluable for response to $\mathrm{R}-\mathrm{CHOP}$ and $\mathrm{R}$-CHOP-like chemotherapy, the overall response

Table 1 Patient's characteristics and their correlations with STAT3 polymorphism genotypes

\begin{tabular}{|c|c|c|c|c|c|c|c|c|c|}
\hline \multirow{2}{*}{$\begin{array}{c}\text { Clinical } \\
\text { parameters }\end{array}$} & \multirow[t]{2}{*}{ No. } & \multicolumn{2}{|c|}{ Genotype } & \multirow[t]{2}{*}{$p$} & \multirow{2}{*}{$\begin{array}{c}\text { Clinical } \\
\text { parameters }\end{array}$} & \multirow[t]{2}{*}{ No. } & \multicolumn{2}{|c|}{ Genotype } & \multirow[t]{2}{*}{$p$} \\
\hline & & $\mathrm{CC}+\mathrm{GG}$ & CG & & & & $\mathrm{CC}+\mathrm{GG}$ & CG & \\
\hline Gender & & & & & IPI score & & & & \\
\hline Male & 82 & 50 & 32 & 0.042 & $0-2$ & 116 & 61 & 55 & 0.867 \\
\hline Female & 84 & 38 & 46 & & $3-5$ & 50 & 27 & 23 & \\
\hline Age & & & & & Bulky mass & & & & \\
\hline$\leq 60$ & 106 & 59 & 47 & 0.364 & $\geq 10 \mathrm{~cm}$ & 33 & 19 & 14 & 0.557 \\
\hline$>60$ & 60 & 29 & 31 & & $<10 \mathrm{~cm}$ & 133 & 69 & 64 & \\
\hline B symptoms & & & & & Localized & & & & \\
\hline Positive & 63 & 31 & 32 & 0.442 & Yes & 27 & 17 & 10 & 0.258 \\
\hline Negative & 103 & 57 & 46 & & No & 139 & 71 & 68 & \\
\hline LDH & & & & & Extra Nodal Site & & & & \\
\hline Positive & 78 & 39 & 39 & 0.464 & $\leq 1$ & 123 & 64 & 59 & 0.669 \\
\hline Negative & 88 & 49 & 39 & & $>1$ & 43 & 24 & 19 & \\
\hline$\beta-2$ MG & & & & & Incidence Site & & & & \\
\hline Positive & 51 & 23 & 28 & 0.091 & Lymph node & 95 & 46 & 49 & 0.170 \\
\hline Negative & 106 & 63 & 43 & & Extra lymph & 71 & 42 & 29 & \\
\hline ESR & & & & & $\mathrm{Ki}-67$ & & & & \\
\hline Positive & 77 & 36 & 41 & 0.132 & $\leq 75$ & 66 & 32 & 34 & 0.329 \\
\hline Negative & 80 & 47 & 33 & & $>75$ & 85 & 48 & 37 & \\
\hline Stage & & & & & Subtype & & & & \\
\hline I-II & 78 & 42 & 36 & 0.839 & GCB & 29 & 18 & 11 & 0.229 \\
\hline III-IV & 88 & 46 & 42 & & Non-GCB & 113 & 56 & 57 & \\
\hline
\end{tabular}


Table 2 Genotype and allele frequencies of STAT3 polymorphisms in 166 Chinese patients with DLBCL

\begin{tabular}{|c|c|c|c|c|c|c|c|c|c|c|}
\hline \multirow[t]{2}{*}{ SNP } & \multicolumn{10}{|c|}{ Genotype frequencies } \\
\hline & Genotype & Freq & Count & Genotype & Freq & Count & Genotype & Freq & Count & Total \\
\hline rs2293152 & CC & 0.187 & 31 & CG & 0.470 & 78 & GG & 0.343 & 57 & 166 \\
\hline \multirow[t]{2}{*}{ SNP } & \multicolumn{10}{|c|}{ Allele frequencies } \\
\hline & Allele & Freq & Count & Allele & \multicolumn{2}{|c|}{ Freq } & \multicolumn{2}{|c|}{ Count } & \multicolumn{2}{|c|}{ Total } \\
\hline rs2293152 & C & 0.447 & 109 & G & \multicolumn{2}{|c|}{0.553} & \multicolumn{2}{|c|}{135} & \multicolumn{2}{|c|}{244} \\
\hline
\end{tabular}

rate (ORR) was $86.1 \%$ (143 of 166 patients), including a complete response (CR) rate of $52.4 \%$ (87 of 166 patients) and a partial response (PR) rate of $33.7 \%$ (56 of 166 patients). As shown in Table 3, higher CR rate was observed in patients with homozygous genotypes than in those with the heterozygous $C G$ genotype $(p=0.032)$. In subgroup analysis based on the GCB/non-GCB molecular types, patients with homozygous genotypes also showed better $\mathrm{CR}$ rate than heterozygous genotype in non-GCB DLBCL patients $(p=0.011)$.

\section{Relationship between the STAT3 genotypes and time to} progression-free survival and overall survival

After a median follow-up time of 913 days (range, 602591 days), 19 (11.4\%) patients relapsed or progressed, and $39(23.5 \%)$ died. Six patients were enrolled in a RAD001 maintenance therapy clinical study, and followup data were not available for 12 patients. Therefore, a total of 148 patients were evaluated for PFS and OS. Patients with homozygous genotypes had a median PFS of 909 days (range, 60-1851) versus 920 days (range, 782591) for the heterozygous CG genotype patients, but the

Table 3 Clinical response to rituximab according to STAT3 polymorphism genotypes

\begin{tabular}{cccc}
\hline Response & \multicolumn{2}{c}{ Genotype } & $p$ \\
\cline { 2 - 3 } & CC + GG & CG & \\
\hline All patients & & & \\
CR & $53(60.2)$ & $34(43.6)$ & 0.032 \\
PR + PD + SD & $35(39.8)$ & $44(56.4)$ & \\
OR & $77(87.5)$ & $66(84.6)$ & 0.591 \\
PD + SD & $11(12.5)$ & $12(15.4)$ & \\
GCB subtype & & & \\
CR & $14(77.8)$ & $8(72.7)$ & 0.758 \\
PR + PD + SD & $4(22.2)$ & $3(27.3)$ & \\
OR & $17(94.4)$ & $11(100)$ & 0.426 \\
PD + SD & $1(5.6)$ & $0(0)$ & \\
Non-GCB subtype & & & \\
CR & $32(57.1)$ & $19(33.3)$ & 0.011 \\
PR + PD + SD & $24(42.9)$ & $38(66.7)$ & \\
OR & $46(82.1)$ & $46(80.7)$ & 0.844 \\
PD + SD & $10(17.9)$ & $11(19.3)$ & \\
\hline
\end{tabular}

differences between these two groups did not reach statistical significance $(p=0.227)$. Interestingly, a longer OR was observed in patients with homozygous genotypes (range, 60-1851) compared with heterozygous CG genotype patients (range, 170-2591; $p=0.022$ ), suggesting that STAT3 polymorphisms could be useful markers to predict the long-term outcome of rituximab treatment (Figure 1). However, this difference was not observed when patients were subdivided into GCB and non-GCB groups (data not shown).

In the multivariate analysis, we attempted to evaluate the following variables on OS: stage, age, LDH level, $\beta 2$ microglobulin level, extranodal involvement, bulky mass, IPI score, B symptoms, and STAT3 polymorphism. This analysis also demonstrated that STAT3 polymorphism was an important determinant of poor prognosis $(p=0.006$; HR 2.787; 95\% CI 1.346-5.773; Table 4).

\section{Discussion}

In this retrospective analysis, STAT3 polymorphisms at rs2293152 were found to associate with $\beta 2-$ MG levels and patient sex. Patients with a CC and GG genotypes at rs2293152 could benefit from rituximab-combined chemotherapy.

Rituximab is a single human mouse chimeric IgG antibody, which combines with the CD20 antigen on the surface of DLBCL cells, directly killing these tumor cells [12]. The antitumor activities of rituximab are mainly believed to be associated with the induction of ADCC and CDC [13]. Polymorphisms in FcyRIIIa, which plays an essential function in ADCC-induced lymphoma cell lysis, were found to relate to the clinical response of rituximab [14]. In a previous study, our group also demonstrated that polymorphisms in the key CDC regulator, gene $C 1 q A$, were related to the efficacy of rituximab in the treatment of DLBCL patients [15]. Furthermore, rituximab has also been suggested to induce apoptosis of lymphoma cells by the inhibition of STAT3 phosphorylation. Various types of tumor cells exhibited constitutively phosphorylated STAT3 within the nucleus, which has been shown to promote uncontrolled malignant tumor growth and relate with a poor prognosis of patients $[16,17]$. However, the effect of STAT3 polymorphisms on the clinical antitumor activities of rituximab has not been reported before. In our study, DLBCL patients with homozygous genotypes in STAT3 


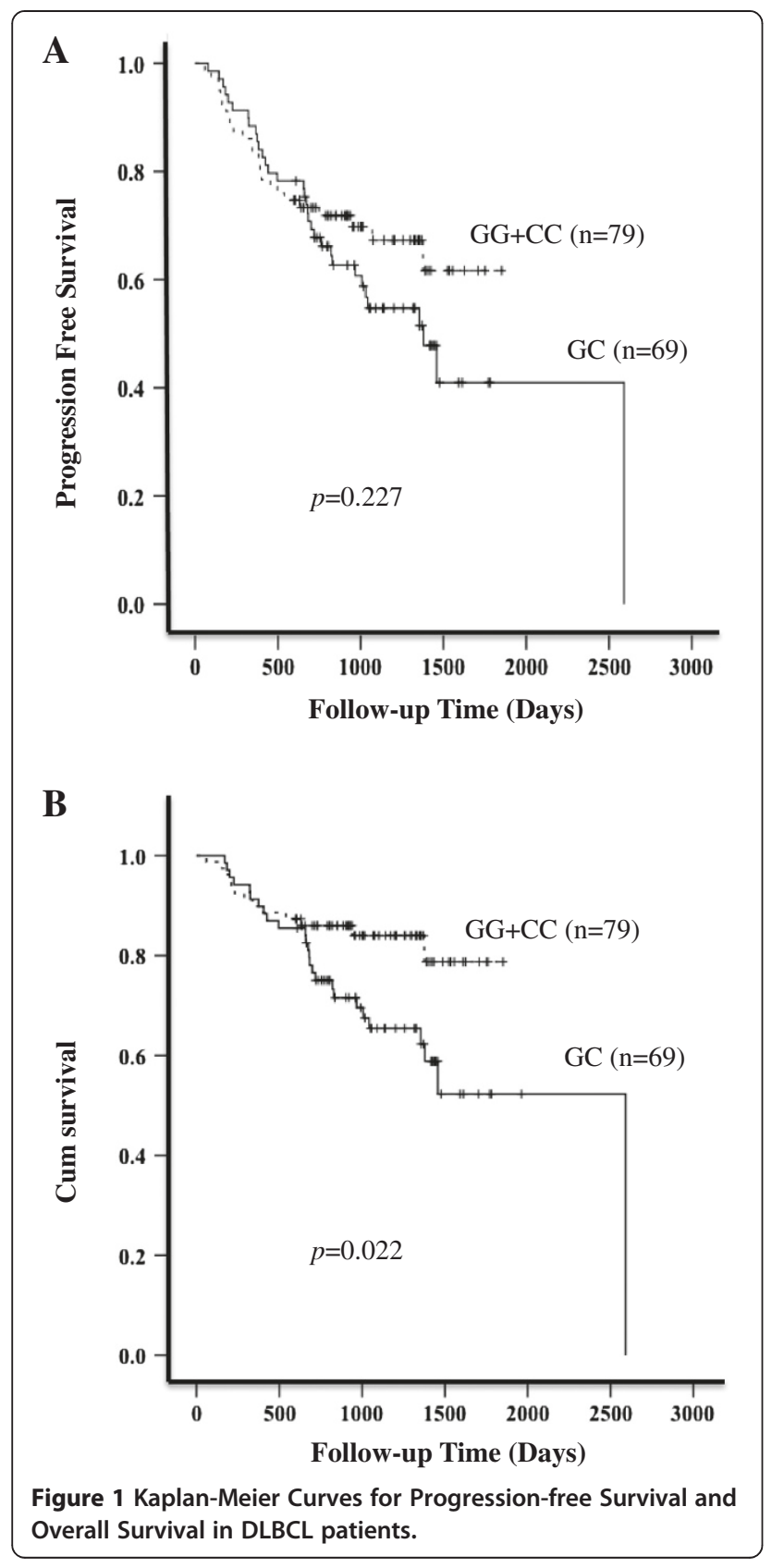

rs2293152 showed better CR rates. Furthermore, the impact of STAT3 polymorphisms on the treatment efficacy was also analyzed in GCB/non-GCB subgroups. Our results showed that patients with homozygous genotypes also showed higher $\mathrm{CR}$ rate than heterozygous genotype in nonGCB DLBCL but not in GCB DLBCL subgroup, which was consistent with previous reports that the activation of STAT3 plays a more important role in ABC-DLBCL than GCB-DLBCL $[18,19]$. On the other hand, the STAT3 polymorphism positions such as rs6503695 and rs12949918 did not show any such relationship with CR and OR rates after rituximab treatment (data now shown).
Table 4 Multivariate analysis of STAT3 polymorphisms on survival

\begin{tabular}{cccc}
\hline Variable & Hazard ratio & $\mathbf{9 5 \% ~ C l}$ & $\boldsymbol{p}$ \\
\hline IPI score & 2.792 & $1.407-5.544$ & 0.003 \\
STAT3 polymorphisms & 2.787 & $1.346-5.773$ & 0.006 \\
B symptoms & 0.420 & $0.210-0.839$ & 0.014 \\
\hline
\end{tabular}

Previously STAT3 polymorphisms had been shown to be suitable as predictive makers to analyze the response to IFN- $\alpha$ in renal cell carcinoma [20]. In that study, the SNP site within STAT3 resulted in a higher expression of STAT3, which might contribute to resistance after IFN- $\alpha$ treatment. The STAT3 SNP site rs2293152 C to G change is an intronic polymorphism, which does not directly introduce amino acid substitution. However, it is increasingly being reported that intron SNPs and silent polymorphisms could also alter the function of target proteins [21,22]. Griseri et al. revealed that a synonymous polymorphism within TTP was associated with protein translation and clinical response rate to herceptin treatment in breast cancer patients [23]. An ERCC1 polymorphism, which induced a codon change from common usage codon AAC to AAT, has also been found to suppress $E R C C 1$ expression, and the objective response rate was much higher after oxaliplatin and 5-fluorouracil combination chemotherapy in colorectal cancer patients [24]. In the previous analysis of rs 2293152 locus of STAT3, Sato et al. reported that the CC genotype was found to be associated with the development of Clone Disease. The polymorphisms of STAT3 in rs2293152 may alter the function of STAT3, further activating the inflammatory signaling pathway and occurrence of the disease [25]. Thus, although rs2293152 is a synonymous polymorphism, this single nucleotide change might affect the phosphorylation level of STAT3, which could contribute to influence the curative effect of rituximab. However, further experimentation is needed to explore the precise mechanism by which STAT3 polymorphisms affect the lymphoma responses to $\mathrm{R}-\mathrm{CHOP}$ chemotherapy.

\section{Conclusions}

The STAT3 polymorphism could be a predictive biomarker related to clinical outcome of DLBCL patients treated with rituximab.

\section{Methods}

Patient characteristics

A total of 166 consenting patients who received R-CHOP or R-CHOP-like chemotherapy (R-COP, R-COPP and $\mathrm{R}-\mathrm{CHOPE}$ ) as a frontline regimen between June 2007 and December 2010 were included in this retrospective study from Peking University Cancer Hospital. All patients 
had $\mathrm{CD} 20^{+}$DLBCL according to the World Health Organization classification, as confirmed by our Department of Pathology. Peripheral blood specimens from all lymphoma patients were obtained before the initiation of therapy. R-CHOP chemotherapy was administered as follows: one course of chemotherapy consisted of an intravenous infusion of $750 \mathrm{mg} / \mathrm{m}^{2}$ cyclophosphamide, $50 \mathrm{mg} / \mathrm{m}^{2}$ adriamycin, and $2 \mathrm{mg}$ vincristine, and oral administration of $100 \mathrm{mg}$ prednisone on days 1 to 5 , which was repeated every 3 weeks. Rituximab $\left(375 \mathrm{mg} / \mathrm{m}^{2}\right)$ was infused for over 4-6 hours on day 1 before CHOP or CHOP-like chemotherapy was started. The response to R-CHOP therapy was evaluated after completion of 2-3 courses of therapy, 1-2 months after completion of all planned therapy, and then every 3 months for the first year and every 6 months thereafter until progression. This retrospective research protocol was approved by our Institutional Review Board.

\section{DNA extraction and genotyping}

Genomic DNA was isolated from whole blood with the Whole Blood Genome DNA Isolation Kit (Omega BioTek, Doraville, GA, USA) according to the manufacturer's instructions. DNA was diluted in water to a final stock concentration of $30 \mathrm{ng} / \mu \mathrm{l}$, and $1 \mu \mathrm{l}$ was used in each PCR reaction. Determination of STAT3 polymorphism genotypes was achieved in a blinded manner on coded specimens by Sanger chain termination sequencing. Briefly, the genomic DNA region of interest was amplified using rs2293152 forward primer $5^{\prime}$ GGTCACCTACATAGTT GATTG3' and reverse primer 5'ACACCCCAGTTGTC TTTCATC3'. An initial denaturation step at $94^{\circ} \mathrm{C}$ for 3 mins was followed by 35 cycles of denaturation at $94^{\circ} \mathrm{C}$ for $30 \mathrm{~s}$, annealing at $56^{\circ} \mathrm{C}$ for $30 \mathrm{~s}$, and extension at $72^{\circ} \mathrm{C}$ for $45 \mathrm{~s}$. The final extension step was for 10 mins. The PCR products were visualized on a $2 \%$ agarose gel. All fragments were purified with the AxyPrep DNA Gel Extraction kit (Axygen Sci. Inc., CA, USA). The purified products were sequenced using an ABI 3730XL Avant Genetic Analyzer (Applied Biosystems Inc., CA, USA).

\section{Definitions}

Clinical responses were determined by physical examination and confirmed by computed tomography or ultrasonography. The latter was only used for evaluating superficial lymph nodes. The responses were scored according to the International Working Group criteria. Overall survival (OS) was measured from day 1 of the first cycle of R-CHOP until death from any cause or the last follow-up available. The progression-free survival (PFS) was calculated from day 1 of the first cycle of $\mathrm{R}-\mathrm{CHOP}$ to disease progression or death from any cause.

\section{Statistical analysis}

The clinical characteristics and response rate of the patients were compared using chi-square and Fisher's exact tests. The Kaplan-Meier method was used to estimate the differences of PFS and OS. The Cox regression model was used to evaluate the prognostic factors. Differences between groups were regarded as significant at $p<0.05$. SPSS16.0 was used for all statistical analysis.

\section{Competing interests}

The authors declare that they have no competing interests.

\section{Authors' contributions}

$J Z$ and YS designed the study and review the final manuscript. YH and ND performed experiment and prepared manuscript. XJ, LF and LP helped to collect specimens and clinical information. YH and ND contribute equally to this work. All authors read and approved the final manuscript.

\section{Acknowledgments}

This work was financially supported by NSFC (No. 81201873 and 81241073), Beijing Natural Science Foundation (No. 7132050) and "985" Basic Research Fund from Peking University.

\section{Author details}

${ }^{1}$ Key laboratory of Carcinogenesis and Translational Research (Ministry of Education), Department of Lymphoma, Peking University Cancer Hospital \& Institute, No.52 Fucheng Road, Haidian District, Beijing 100142, China. ${ }^{2}$ Department of Oncology, Affiliated Hospital of Guiyang Medical College, Guizhou Cancer Hospital, No.1 Beijing West Road, Yunyan District, Guiyang 550003, China. ${ }^{3}$ Department of Internal Medicine Oncology, Peking University First Hospital, No.8 Xishiku Street, Xicheng District, Beijing 100034, China.

Received: 2 January 2014 Accepted: 10 March 2014

Published: 13 March 2014

\section{References}

1. Campo E, Swerdlow SH, Harris NL, Pileri S, Stein H, Jaffe ES: The 2008 WHO classification of lymphoid neoplasms and beyond: evolving concepts and practical applications. Blood 2011, 117(19):5019-5032.

2. Sehn LH, Donaldson J, Chhanabhai M, Fitzgerald C, Gill K, Klasa R, MacPherson N, O'Reilly S, Spinelli JJ, Sutherland J, Wilson KS, Gascoyne RD, Connors JM: Introduction of combined CHOP plus rituximab therapy dramatically improved outcome of diffuse large B-cell lymphoma in British Columbia. J Clin Oncol 2005, 23(22):5027-5033.

3. Smith MR: Rituximab (monoclonal anti-CD20 antibody): mechanisms of action and resistance. Oncogene 2003, 22(47):7359-7368.

4. Zhong Z, Wen Z, Darnell JEJ: Stat3: a STAT family member activated by tyrosine phosphorylation in response to epidermal growth factor and interleukin-6. Science 1994, 264(5155):95-98.

5. Al Zaid Siddiquee K, Turkson J: STAT3 as a target for inducing apoptosis in solid and hematological tumors. Cell Res 2008, 18(2):254-267.

6. Ding BB, Yu JJ, Yu RY, Mendez LM, Shaknovich R, Zhang Y, Cattoretti G, Ye BH: Constitutively activated STAT3 promotes cell proliferation and survival in the activated B-cell subtype of diffuse large B-cell lymphomas. Blood 2008, 111(3):1515-1523.

7. Wu ZL, Song YQ, Shi YF, Zhu J: High nuclear expression of STAT3 is associated with unfavorable prognosis in diffuse large B-cell lymphoma. J Hematol Oncol 2011, 4(1):31

8. Alas S, Bonavida B: Rituximab inactivates signal transducer and activation of transcription 3 (STAT3) activity in B-non-Hodgkin's lymphoma through inhibition of the interleukin 10 autocrine/paracrine loop and results in down-regulation of $\mathrm{Bcl}-2$ and sensitization to cytotoxic drugs. Cancer Res 2001, 61(13):5137-5144.

9. Byrd JC, Kitada S, Flinn IW, Aron JL, Pearson M, Lucas D, Reed JC: The mechanism of tumor cell clearance by rituximab in vivo in patients with B-cell chronic lymphocytic leukemia: evidence of caspase activation and apoptosis induction. Blood 2002, 99(3):1038-1043.

10. Kreil S, Waghorn K, Ernst T, Chase A, White H, Hehlmann R, Reiter A Hochhaus A, Cross NC: A polymorphism associated with STAT3 
expression and response of chronic myeloid leukemia to interferon alpha. Haematologica 2010, 95(1):148-152.

11. Chen Y, Lan Q, Zheng T, Zhao N, Holford TR, Lerro C, Dai M, Huang H, Liang J, Ma S, Leaderer B, Boyle P, Chanock S, Rothman N, Zhang Y: Polymorphisms in JAK/STAT signaling pathway genes and risk of non-Hodgkin lymphoma. Leuk Res 2013, 37(9):1120-1124.

12. Hagemeister F: Rituximab for the treatment of non-Hodgkin's lymphoma and chronic lymphocytic leukaemia. Drugs 2010, 70(3):261-272.

13. Golay J, Zaffaroni L, Vaccari T, Lazzari M, Borleri GM, Bernasconi S, Tedesco F, Rambaldi A, Introna M: Biologic response of B lymphoma cells to anti-CD20 monoclonal antibody rituximab in vitro: CD55 and CD59 regulate complement-mediated cell lysis. Blood 2000, 95(12):3900-3908.

14. Cartron G, Dacheux L, Salles G, Solal-Celigny P, Bardos P, Colombat P, Watier $H:$ Therapeutic activity of humanized anti-CD20 monoclonal antibody and polymorphism in IgG Fc receptor FcgammaRilla gene. Blood 2002, 99(3):754-758.

15. Jin $X$, Ding $H$, Ding $N$, Fu Z, Song $Y$, Zhu J: Homozygous A polymorphism of the complement C1qA276 correlates with prolonged overall survival in patients with diffuse large B cell lymphoma treated with R-CHOP. J Hematol Oncol 2012, 5(1):51-56.

16. Bromberg JF, Wrzeszczynska MH, Devgan G, Zhao Y, Pestell RG, Albanese C, Darnell JEJ: Stat3 as an oncogene. Cell 1999, 98(3):295-303.

17. Yu H, Pardoll D, Jove R: STATs in cancer inflammation and immunity: a leading role for STAT3. Nat Rev Cancer 2009, 9(11):798-809.

18. Scuto A, Kujawski M, Kowolik C, Krymskaya L, Wang L, Weiss LM, Digiusto D, Yu H, Forman S, Jove R: STAT3 inhibition is a therapeutic strategy for ABC-like diffuse large B-cell lymphoma. Cancer Res 2011, 71(9):3182-3188.

19. Huang $X$, Meng B, labal J, Ding BB, Perry AM, Cao W, Smith LM, Bi C, Jiang C, Greiner TC, Weisenburger DD, Rimsza L, Rosenwald A, Ott G, Delabie J, Campo E, Braziel RM, Gascoyne RD, Cook JR, Tubbs RR, Jaffe ES, Armitage JO, Vose JM, Staudt LM, McKeithan TW, Chan WC, Ye BH, Fu K: Activation of the STAT3 signaling pathway is associated with poor survival in diffuse large B-cell lymphoma treated with R-CHOP. J Clin Oncol 2013, 31(36):4520-4528.

20. Ito N, Eto M, Nakamura E, Takahashi A, Tsukamoto T, Toma H, Nakazawa H, Hirao Y, Uemura H, Kagawa S, Kanayama H, Nose Y, Kinukawa N, Nakamura T, Jinnai N, Seki T, Takamatsu M, Masui Y, Naito S, Ogawa O: STAT3 polymorphism predicts interferon-alfa response in patients with metastatic renal cell carcinoma. J Clin Oncol 2007, 25(19):2785-2791.

21. Kimchi-Sarfaty C, Oh JM, Kim IW, Sauna ZE, Calcagno AM, Ambudkar SV, Gottesman MM: A "silent" polymorphism in the MDR1 gene changes substrate specificity. Science 2007, 315(5811):525-528.

22. Sauna ZE, Kimchi-Sarfaty C, Ambudkar SV, Gottesman MM: Silent polymorphisms speak: how they affect pharmacogenomics and the treatment of cancer. Cancer Res 2007, 67(20):9609-9612.

23. Griseri P, Bourcier C, Hieblot C, Essafi-Benkhadir K, Chamorey E, Touriol C, Pages G: A synonymous polymorphism of the Tristetraprolin (TTP) gene, an AU-rich mRNA-binding protein, affects translation efficiency and response to Herceptin treatment in breast cancer patients. Hum Mol Genet 2011, 20(23):4556-4568.

24. Viguier J, Boige V, Miquel C, Pocard M, Giraudeau B, Sabourin JC, Ducreux M, Sarasin A, Praz F: ERCC1 codon 118 polymorphism is a predictive factor for the tumor response to oxaliplatin/5-fluorouracil combination chemotherapy in patients with advanced colorectal cancer. Clin Cancer Res 2005, 11(17):6212-6217.

25. Sato K, Shiota M, Fukuda S, Iwamoto E, Machida H, Inamine T, Kondo S, Yanagihara K, Isomoto H, Mizuta Y, Kohno S, Tsukamoto K: Strong evidence of a combination polymorphism of the tyrosine kinase 2 gene and the signal transducer and activator of transcription 3 gene as a DNA-based biomarker for susceptibility to Crohn's disease in the Japanese population. J Clin Immunol 2009, 29(6):815-825.

doi:10.1186/1475-2867-14-25

Cite this article as: Hu et al:: Genetic polymorphisms of STAT3

correlated with prognosis in diffuse large B-cell lymphoma patients treated with rituximab. Cancer Cell International 2014 14:25.

\section{Submit your next manuscript to BioMed Central and take full advantage of:}

- Convenient online submission

- Thorough peer review

- No space constraints or color figure charges

- Immediate publication on acceptance

- Inclusion in PubMed, CAS, Scopus and Google Scholar

- Research which is freely available for redistribution

Submit your manuscript at www.biomedcentral.com/submit 